\title{
A ALIENAÇÃO EM KARL MARX: UM CONCEITO HEGELIANO?*
}

\author{
Maria Cristina Candal Poli*
}

SINTESE - Este artigo tem por objetivo ilustrar a relação de Marx com a filosofia hegeliana a partir do conceito de alienação. A autora procura demonstrar que o lugar metodológico deste conceito na argumentação filosófica de Hegel e Marx representa a diferença entre as concepções idealista e materialista respectivas. Porém, sublinha igualmente a. semelhança entre ambos pensadores que têm no conceito de alienação os limites da tematização filosófica do mundo concreto.
ABSTRACT - This article intends to illustrate the relation between Marx's and Hegel's philosophy starting from the concept of alienation. The authoress aims at demonstrating that the methodological site of this concept in Marx's and Hegel's philosophical argumentations represents the difference between the idealist and the materialist conceptions. However, she also emphasizes the similarity between both thinkers, for they see in the concept of alienation the limits of the philosophical thought about the concrete world.

\section{Introdução}

Se tentássemos resumir, numa frase, o projeto filosófico de Marx, talvez pudéssemos dizer que seu objetivo é fazer a crítica do capitalismo como sistema social demonstrando a impossibilidade de o capital se estabelecer como princípio totalizador das relações sociais. De igual forma, com a mesma intenção de síntese, poderíamos indicar o conceito de alienação como o fundamento da crítica marxiana ao capital. A escolha deste conceito se deve ao fato de ele representar, dentro da argumentação marxiana, a exclusão de categorias humanas das relações regidas pelo capital e, assim, responder às aspirações do filósofo-economista de apontar as falhas inerentes ao princípio do capitalismo.

Porém, longe de a alienação ser um conceito original em Marx, já Hegel o concebe como elemento fundamental da Dialética do Reconhecimento na Filosofia do Espírito. A adoção de conceitos hegelianos e do método dialético de Hegel, é fato comum no pensamento marxiano sendo de todos conhecido o estreito vínculo

\footnotetext{
- Trabalho apresentado em conclusão à disciplina "A metafisica enquanto crítica em Marx", ministrada pelo prof. Hans-Georg Flickinger.

* Psicóloga. Mestanda do Curso de Pós-Graduação em Filosofia da PUCRS.
} 
entre estes dois grandes pensadores. Com efeito, Marx é amplamente considerado como o principal herdeiro da filosofia hegeliana, porém é também seu mais incisivo crítico. A filosofia marxiana parte da argumentação teórico-metodológica de Hegel mas a modifica substancialmente.

Estas alterações, que se fazem notar ao longo de toda a obra de Marx, acompanham as modificações promovidas por ele no seu próprio projeto filosófico. A evolução temática do conceito de alienação é exemplar neste sentido. Ou seja, parece-nos ser possível perceber, nas diferentes tematizações que Marx confere a este conceito, a evolução de suas concepções teórico-práticas, bem como as alterações metodológicas operadas na filosofia hegeliana na qual o filósofo ancora seus pensamentos.

Nos Manuscritos de Paris, por exemplo, o conceito de alienação associa-se à tematização proposta por Marx do trabalho humano na forma como este aparece na realidade social capitalista. Já nos Grundrisse, texto posterior, ele é o conceitochave a direcionar a busca pelas categorias determinantes do jogo social dirigido pela relação capital-trabalho. Em ambos momentos é na obra hegeliana, nos textos Fenomenologia do Espírito e Ciência da Lógica respectivamente, que Marx vai buscar a fundamentação metodológica da sua argumentação, modificando-a para os seus propósitos.

É porém na última obra de Marx, O Capital, que a originalidade das suas contribuições político-filosóficas é expressa de forma madura. Nesta, o autor concretiza sua "revolução" no método hegeliano, pela materialização da dialética, e apresenta os fundamentos histórico-constitutivos que tornam (im)possível o capital como princípio, formador e deformador, das relações sociais. A alienação, como intuição primeira das deformações sociais, é formulada de forma muito mais ampla pela exclusão da subjetividade đas relações sociais permeadas pelo capital ${ }^{1}$.

Entendendo, pois, ser possível perceber a evolução da obra de Marx pelas diferentes formas de conceber a alienação, propomo-nos a estudar a forma como o filósofo remete nos Manuscritos de Paris ${ }^{2}$, através deste conceito, à duplicidade de sua relação com seu pai intelectual, Hegel. Nossa ênfase recairá sobre a dívida de Marx para com a obra hegeliana, procurando na Fenomenologia do Espirito a base metodológica e conceitual desta primeira formulação marxiana da alienação.

\section{Hegel: alienação e reconhecimento}

A Fenomenologia do Espírito de Hegel e os Manuscritos de Paris de Marx são ambos textos que marcam na trajetória destes dois filósofos o final da juventude e inicio da maturidade intelectual. Da mesma forma, em ambos encontramos a expectativa dos seus autores de dar substância teórica a seus anseios políticos. Cada qual em sua época, Hegel e Marx são os dois grandes filósofos a tematizar a realidade político-social, amarrando filosofia e história e estabelecendo este laço como um traço indelével da era moderna. Hegel deu o impulso inicial; Marx o radicali-

Alienação, no sentido latu, significa a tentativa de formulação, ou de "bordeamento", via negativa, do que Flickinger (1984) denominou "sujeito desaparecido".

2 Manuscritos econômico-filosóficos, pricipalmente aquele referente a "Crítica da dialética e da filosofia hegeliana em geral". In: Os pensadores, p.38-54. 
zou, derivando todas as conseqüências de um pensamento engajado na concretude do mundo vivido.

De fato, os ideais do jovem Hegel figuram na seqüência de uma sociedade revolucionária que tinha na Liberdade, Igualdade e Fraternidade seu grito de ordem. Ordem que estabelece o caráter paradoxal de dita sociedade pois desenha a revolução, de forma anacrônica, como a busca de uma nova forma de organização - a burguesa - que em termos repressivos em nada deixa a desejar a sua antecessora - a sociedade feudal.

A obra hegeliana reflete o seu tempo. Jovem revolucionário, Hegel, ao escrever a Fenomenologia do Espínto, abandona suas teses contextuais permeadas de espírito crítico, sobre política e religião, e lança-se ao projeto de construir uma filosofia segundo as exigências sistemáticas de uma verdadeira ciência. Seu projeto é o próprio paradoxo em questão: tratar do absoluto, da totalidade, tomando a liberdade como princípio normativo. Colocando a dificuldade em forma de pergunta: como conceber a liberdade dentro de um sistema onde a argumentação é toda ela derivada de forma imanente a seu próprio princípio?

A resposta a esta questão remete à essencialidade do método de Hegel para a construção do sistema. Somente na dialética, tal qual formulada pelo filósofo, encontramos a possibilidade de tematização e superação da contradição liberdadetotalidade; contradição própria da realidade sóciopolítica vivida por Hegel. Assim, a originalidade da dialética hegeliana é a apropriação da contradição como mola propulsora do desenvolvimento do sistema. Além disso, por se tratar de um sistema auto-expositivo, a contradição só pode derivar de um movimento reflexivo imanente. A liberdade está pois justamente na capacidade de auto-referência do absoluto pelo reconhecimento (Anerkennung) das mediações lógicas que the determinam. A propriedade de reconhecer (anerkennen) é própria do Espírito, ou seja, do absoluto em sua forma mais evoluída, isto é, mais concreta e determinada $e$, por isto, é somente neste que a liberdade se efetiva.

Hegel trata do Espírito em dois momentos na sua obra, na Fenomenologia do Espírito, primeiro grande livro da filosofia hegeliana e adotado como uma introdução ao seu sistema e, dentro do próprio sistema, como termo final da evolução do absoluto. No primeiro, do qual nos ocuparemos a seguir, a preocupação de Hegel é demonstrar o percurso da consciência ingênua ao saber absoluto fundamentado na autodeterminação da consciência. Sua argumentação visa estabelecer a base constitutiva das experiências aparentes da consciência demonstrada através da reflexão da consciência sobre estas próprias experiências.

À diferença de seus escritos propriamente sistemáticos, na Fenomenologia do Espírito Hegel pensa o aparecer da consciência não como constituinte da essência do processo, ou seja, necessário como primeiro momento da essência, mas como enganador, como um desvio da consciência no seu caminho rumo à verdade ${ }^{3}$. Assim, a trajetória da consciência ingênua ao saber é traçada por Hegel como a paulatina eliminação dos equívocos da aparência. A medida normativa é dada pela própria consciência, pelo seu caráter reflexivo, que percebe e corrige os erros da experiência imediata. Ou seja, é através da tomada de consciência acerca do en-

3 Ver Flickinger, 1993. 
gano, possibilidade dada pela capacidade reflexiva da consciência, que o processo de aprendizagem engendra seu rumo. Desta forma, é a própria autonomia do saber, como expressão conceitual da verdade, que Hegel vislumbra como efeito do ser auto-reflexivo da consciência.

Cabe, porém, perguntar como é possível o engano se partimos de uma argumentação imanente à própria consciência. Como sabemos, o objetivo de Hegel na Fenomenologia do Espírito é demonstrar o conceito de verdade como o lugar da unidade entre sujeito e objeto do conhecimento. Para o filósofo, a possibilidade de fundamentar a autonomia do saber se baseia, necessariamente, na: capacidade imanente da consciência de alcançá-lo por seus próprios meios. Ou seja, ao nível do saber o conteúdo da consciência tem de corresponder a sua própria forma. Porém, ao nível da consciência ingênua, início da Fenomenologia do Espírito, sujeito e objeto estão cindidos, a consciência toma a realidađe objetiva como externa a si e a apreende desta forma. A experiência enganadora da realidade imediata é pois uma contingência inicial do processo reflexivo da consciência, um "erro" de procedimento de uma consciência que se objetifica mas ainda não é capaz de reconhecer (anerkennen) a si no objeto.

A peculiaridade desta argumentação e deste método dentro da obra hegeliana nos permite vislumbrar a conceitualização da alienação de forma particular na Fenomenologia do Espírito. A questão pode ser situada, conforme nos aponta Jarczyk ${ }^{4}$, através do uso por Hegel de dois termos distintos, Aeusserung e Entäusserung, para significar o momento do processo reflexivo em que a consciência se objetifica. Estes dois conceitos, traduzidos por Jarczyk e Labarrière para o francês, respectivamente por externação e exteriorização, denotam formas diferentes de objetificação da consciência, sendo que o primeiro não implica, necessariamente como o segundo, o retorno reflexivo da exterioridade a si. Ou seja, a Aeusserung é o lugar argumentativo onde a alienação aparece como possibilidade.

\footnotetext{
"Sabemos que Aeusserung designa a simples saída de si de uma interioridade, sem que seja decidido se esta 'saída' conduzirá ou não a uma autêntica determinação reflexiva de si mesmo (neste caso se falará de Entäussenung) ou a uma perda de si sem retorno em uma realidade definitivamente estrangeira (o que seria, no sentido próprio, uma Entfrendung, uma alienação)."
}

Assim, a experiência enganadora da consciência ingênua nada mais é que uma "falha" no processo reflexivo da consciência que conduz a uma objetificação sem retorno, uma alienação.

Já a possibilidade de que a Aeusserung conduza não à alienação mas sim a uma verdadeira determinação reflexiva de si é dada, como já dissemos, pelo movimento de reconhecimento (Anerkennung). O papel central que a Anerkennung ocupa no capítulo referente à autoconsciência não é casual: trata-se do momento chave onde a consciência vislumbra pela primeira vez a unidade de sujeito e objeto. Ao encontrar a si mesma onde supunha só haver exterioridade, a consciência se reconhece (anerkennen) como determinante do processo constitutivo do saber.

\footnotetext{
Jarczyk, 1984.

Idem, p.118.

"Falha" no sentido de "abertura" do processo necessitário a uma derivação contingente.
} 
Pelo reconhecimento (Anerkennung) a exterioridade perde seu caráter alienante, enganador e se torna alteridade constitutiva do "si mesmo". Deixa de ser senhor e passa a ser semelhante ${ }^{7}$..

\section{Marx e a alienação de Hegel}

O paradoxo interno à teoria hegeliana, qual seja, a fundamentação da liberdade como princípio imanente a uma argumentação sistemática e totalizante, levou os jovens hegelianos, à época de Marx, a uma convivência conflitiva com a obra de seu mestre. A expressão maior de tal conflito era a interpretação dos escritos políticos tardios de Hegel (principaimente a Filosofia do Direito) onde a aplicação dos princípios lógico-sistemáticos à realidade político-social pareciam fundamentar o status quo do Império prussiano sem o expor a crítica necessária que uma filosofia supostamente libertária deveria realizar.

Marx vê o problema e o assume em sua relação dúbia com a obra hegeliana: por um lado, admira na filosofia de Hegel a sua capacidade de fundamentação reflexiva da autonomia e da liberdade, ou seja, a sua capacidade imanente de argumentação; por outro, condena as conseqüências nefastas a que o idealismo de seu mestre chegou ao perder a capacidade de crítica da realidade social.

Para Marx, a filosofia é a expressão ideológica das condições materiais da sociedade sendo, portanto, o lugar de crítica possivel ao espelhar a constituição objetiva da realidade social. Em outras palavras, ou nos termos em que Marx concebe o capital, a expressão teórica das condições da constituição da realidade social propicia a descoberta e a crítica das insuficiências de tal realidade ao apresentar, via negativa, as falhas em seu principio fundamentador. Esta concepção materialista da filosofia, em oposição ao idealismo hegeliano, não impede que Marx mantenha sua admiração pelo método dialético de Hegel e o adote como expressão das contradições sociais. Porém, é no impossível do sistema hegeliano, na aporia da imanência da liberdade, que Marx funda a originalidade de seu pensamento ao entender a insuficiência do princípio como a insuficiência mesma do sistema social.

Sob este prisma, a leitura marxiana da Fenomenologia do Espírito revela todos os seus matizes. A dialética do aparecer enganoso ganha relevo na interpretação de Marx pois encontra-se aí a possibilidade de uma crítica interna à própria teoria e portanto à realidade sociocultural que ela expressa. O que está em jogo, na argumentação de Hegel, é a aparência enganosa da experiência imediata da consciência que é supra-assumida pelo saber absoluto onde sujeito e objeto se coadunam na figura da autoconsciência. Para Marx, é o reconhecimento necessário da dependência da teoria às condições materiais da realidade social, ou seja, da práxis como alteridade constitutiva do teórico.

De acordo com a crítica de Marx ao método da Fenomenologia do Espírito, Hegel cai numa espécie de petição de princípio ao propor a superação da alienação através de categorias abstratas retiradas de dentro da própria argumentação

Fazemos referência aqui à figura do Senhor e do Escravo através da qual Hegel apresenta, no capítulo da Autoconsciência, a luta pelo reconhecimento (der Kampf des Anerkennung). 
filosófica. No entender de Marx, a própria filosofia passa a ser a expressão da alienação, pois fundamenta a efetividade do homem em um ser abstrato - o saber absoluto - e não através de categorias sócio-materiais concretas. O movimento reflexivo encontraria neste ponto o seu limite, na medida em que impede a verdadeira tematização de conteúdos concretos, externos ao pensamento. Conforme Marx, na fenomenologia hegeliana:

"[...] o homem autoconsciente, na medida em que reconheceu e superou como autoalienação o mundo espiritual (ou o modo de existência espiritual geral de seu mundo), confirma-o, no entanto, novamente nesta figura alienada e a apresenta como seu verdadeiro modo de existência, restaura-a, pretende estar junto a si em seu ser-outro enquanto tal.".8

Por outro lado, Marx concede todos os méritos a Hegel pelo caráter processual da dialética que imprime à alienação uma forma positiva, como um momento necessário e que ao ser superado constitui o homem enquanto tal. Esta função atribuída por Marx à alienação no sistema hegeliano refere-se ao movimento de exteriorização inerente ao processo reflexivo. Segundo ele:

"A grandeza da fenomenologia hegeliana e de seu resultado final - a dialética da negatividade na qualidade de princípio motor e gerador - consiste, de uma parte, em que Hegel compreenda a autogeração do homem como processo, a objetivação como desobjetivação, alienação e superação desta alienação; em que compreenda então a essência do trabalho e conceba o homem objetivado, verdadeiro, pois esse é o homem efetivo como resultado do seu próprio trabalho."

Ou seja, o trabalho do conceito ${ }^{10}$ em Hegel, que percorre a dialética da reflexão, tem o mérito reconhecido por Marx de expressar a constituição efetiva do homem através do seu trabalho concreto.

Esta duplicidade na relação de Marx com o movimento de objetificação, inerente ao método reflexivo da dialética de Hegel na Fenomenologia, remete às diferenças entre os conceitos de exteriorização (Entäusserung) e externação (Aeusserung) descritas acima. Ou seja, Marx parece apontar que a verdadeira alienação se situa na inequivocidade de um movimento reflexivo necessário e imanente que desconsidere as condições materiais de sua realização. $\mathrm{O}$ que em Hegel remete a uma superação necessariamente exitosa da objetificação, uma vez que tem suas determinações adscritas pela lógica interna do pensamento, seria o lugar mesmo da alienação na filosofia marxiana.

Assim, para Marx a possibilidade concreta de superação da alienação se daria no espaço aberto onde a teoria expressa uma insuficiência conceitual, onde a racionalidade apela para as condições históricas de sua possibilidade. Em outras palavras, para Marx, a superação da alienação, ou seja, a apreensão da objetificação do homem como momento do processo constituinte da sua própria efetividade, é a assunção do papel necessário de uma exterioridade, de um mais além do principio, determinada por contingências materiais e históricas.

\footnotetext{
Marx, Manuscritos econômicos-filosóficos. In: Os pensadores, p.48.

9 Marx, Manuscritos econômicos-filosóficos. In: Os pensadores, p.43.

10 Expressão utilizada por Jarczyk, 1984.
} 
Temos, pois, estabelecida a perspectiva filosófica de Marx, a partir da análise do conceito de alienação. Por um lado, a filosofia marxista apóia-se na obra hegeliana pela perspectiva metodológica, formulando o processo de constituição das condições histónico-materiais da realidade social à semelhança do percurso do conceito em Hegel. Neste âmbito, a alienação enquanto conceito interno à dialética do aparecer enganador formulada por Hegel é adotada por Marx como expressão de um elemento chave nas relações sociais. Porém, Marx acrescenta ao método hegeliano a perspectiva crítica que consiste em demonstrar, via negativa, a exclusão das categorias humanas - a alienação do homem no processo produtivo ao se levar o princípio totalizador da realidade social, o capital, às últimas conseqüências. Para tanto, Marx se vale da crítica à própria filosofia hegeliana que, desde semelhante perspectiva totalizante, abre mão de sua função libertária para transformar-se em mais um elemento de alienação do homem.

\section{Bibliografia consultada}

CODO, Wanderley. O que é alienação. (Col. Primeiros Passos). São Paulo: Brasiliense, 1985.

FLICKINGER, Hans Georg. "O sujeito desaparecido na teoria marxiana". In: Filosofia politica. v. 1. Porto Alegre: L\&PM, 1984. p. 9-24. . Marx - nas pistas da desmistificação filosófica do capitalismo. Porto Alegre: L\&PM, 1985. . Marx e Hegel - o porăo de uma filosofia social. Porto Alegre: L\&PM : CNPq, 1986. "A verdade do aparecer - reflexões sobre um conceito-chave da filosofia hegeliana". In: STEIN, E., DE BONI, L. Dialética e liberdade- Festschnift em homenagem a Carlos R. Cime Lima. Petrópolis: Vozes; Porto Alegre:: Suhrkamp, 1989.

JARCZYK, Gwendoline. "O conceito do trabalho e o trabalho do conceito". Editora da UFRGS, 1993.

HEGEL, G. W. F. Phänomenologie des Geistes. Werke 3. Frankfurt am Main In: Filosofia política. v. 1. Porto Alegre: L\&PM, 1984. p. 115-129.

MARX, Karl. Manuscritos econômico-filosóficos. In: Coleção Os pensadores- Karl Marx. v. XXXV. Trad. José Carlos Bruni. São Paulo: Abril Cultural, 1974. . Manuscritos econômico-filosóficos. Trad. Artur Morão. Lisboa: Edições 70, 1964. 